\title{
Analysis of the cost-effectiveness of the implementation of Indoor Residual Spraying and distribution of Long-Lasting Insecticidal Nets in the municipality of Kouandé and municipality of Copargo in Benin
}

\author{
Charles Patrick Makoutodé ${ }^{*}$, Martine Audibert ${ }^{2}$ and Achille Massougbodji ${ }^{3}$
}

\begin{abstract}
Background: In Benin, malaria was the leading cause of hospital consultation for children less than 5 years old (47.2\%), and for all patients not hospitalized (42.3\%). Its incidence among those who attended a health facility was respectively $42.9 \%$ and $17 \%$. To address this problem, the National Program for the Fight against Malaria undertook, in 2011, a mass campaign of distribution of Long-Lasting Insecticidal Nets (LLINs). In addition to this strategy, the program decided to implement Indoor Residual Spraying in 7 of the 9 municipalities of Atacora department, which is one of the most malaria endemic areas. The objective of this study was to see if adding the IRS to the LLINs (municipality of Kouandé) strategy is cost-effective, as compared to the LLINs-only strategy (municipality of Copargo), in highly malaria endemic areas.
\end{abstract}

Method: This study was a cross-sectional study of the implementation of the IRS from June 2011 to July 2011. Regarding the selection of health workers, managers of the malaria program, and partners of implementation of the IRS, a reasoned choice was made. The data collection consisted mainly of a series of interviews with people responsible for resource management and the exploitation of documents provided by them.

Results: After the implementation of LLNS + IRS the annual incidence of malaria in health facilities decreased significantly at Kouandé-Centre and at Guilmaro. In the same period it increased significantly at Copargo- Centre, and decreased at Pabégou.

The average cost per malaria case prevented (CE) was respectively 85,572.4 FCFA at Copargo Centre, 38,932.6 FCFA at Kouandé Centre, 15,940.6 FCFA at Pabégou and 174,728.5 FCFA at Guilmaro. According to the results, the CE ratio at Kouandé-Centre is lower than the CE ratio at Copargo- Centre and the CE ratio at Guilmaro is higher than the CE ratio at Pabégou.

The LLINs + IRS strategy is more cost effective in urban areas than the LLINs-only strategy. The opposite result is observed in rural areas.

Conclusion: The LLINs + IRS strategy is cost effective in highly endemic areas both urban and rural, if communities sleep in sprayed structures and use LLINs even when it is hot.

Keywords: Malaria, Cost-effectiveness, Indoor Residual Spraying, Long-Lasting Insecticidal Nets, Benin

\footnotetext{
* Correspondence: makoutodepatrick@yahoo.fr

'Interdisciplinary Graduate School: Space, Culture and Development,

Faculty of Humanities Arts and Social Sciences, University of Abomey-Calavi,

01 BP526 Cotonou, Benin

Full list of author information is available at the end of the article
}

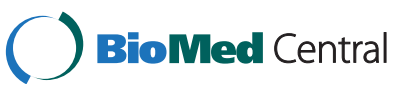

(c) 2014 Makoutodé et al.; licensee BioMed Central Ltd. This is an Open Access article distributed under the terms of the Creative Commons Attribution License (http://creativecommons.org/licenses/by/4.0), which permits unrestricted use, distribution, and reproduction in any medium, provided the original work is properly credited. The Creative Commons Public Domain Dedication waiver (http://creativecommons.org/publicdomain/zero/1.0/) applies to the data made available in this article, unless otherwise stated. 


\section{Introduction}

Malaria is a major public health and development problem. The number of malaria cases was estimated at 207 million worldwide in 2012 (uncertainty range: 135 to 287 million). According to the estimations the majority of cases (80\%) are located in sub-Saharan Africa. Globally, the number of deaths has been estimated at 627,000 for 2012 (uncertainty range: $473,000-789,000$ ) of which $90 \%$ occur in sub-Saharan Africa. Most of these deaths (77\%) affected children under 5 years of age [1].

In Benin, the incidence of malaria was estimated to be 17\% among those who attended a health facility in 2012. This incidence was $42.9 \%$ for children under 5 [2].

In order to improve these indicators, the National Program for Fight against Malaria (PNLP) decided to carry out the Indoor Residual Spraying strategy (IRS) alongside the Long-Lasting Insecticidal Nets (LLINs) strategy in high malaria endemic areas. This intervention was fully funded by USAID. For this experiment, the local government area of Atacora was selected. This area has the highest malaria parasite incidence, $51.1 \%$, against the national average of $28.4 \%$ [3]. It is characterized by a single period of malaria transmission in the year. This means that one spray session per year should be sufficient to cover the period of malaria transmission.

Malaria is considered as a hindrance to the development of most of the countries affected by it because of the Disability Adjusted Life Year (DALY) loss, the loss of life, and the loss of working days it causes. Despite the existence of prevention and treatment means, the number of people who die from the disease each year in the world is estimated at about 1,000,000 [4].

Malaria also has economic consequences for households because of the exposure to financial risk. Indeed, according to the results of economic cost studies, usually the financial burden of malaria episodes (particularly severe ones) significantly impacts household income and especially the availability of savings.

The aim of this study is to check whether, in high malaria endemic areas, the joint strategy (IRS + LLINs) is more cost effective than the LLINs-only strategy.

\section{Materials and methods}

\section{Selection and sites of the study}

The study was conducted in two municipalities, Kouandé and Copargo, in Benin. In each municipality, one urban municipality and one rural municipality were selected, based on the criterion of the busiest health centre in 2010. The municipality of Kouandé covers an area of $4,500 \mathrm{sq} \mathrm{km}$ ' and is bordered by the municipalities of Kérou (North), Tanguiéta (Northwest), Copargo, Djougou and Boukombé (South), and the urban commune of Natitingou (Southwest). The climate, Sudano-Guinean, is characterized by a rainy season, from mid-April to
mid-October and a dry season from mid-October to mid-April. The municipality has a dense river system, consisting of a several perennial rivers and streams, and seasonal streams. The Bariba constitute the majority of the local socio-cultural group (43.6\%), followed by the Bètamaribè (24\%), both are farmers. Then comes the Fulani group (17.9\%) consisting mainly of breeders, and the Yom Lokpa (7.2\%). Other socio-cultural groups represent $7.2 \%$. The main religions are Islam (38.5\%), traditional religions (30.2\%) and Catholicism (14.8\%) [5].

Since 2010, the Regional Institute of Public Health (IRSP) with the financial support of USAID has ensured the strengthening of epidemiological surveillance of malaria in the municipality of Kouandé. This municipality was selected to ensure that good quality data was collected.

The study of the geography of this municipality focused on the physical nature of the habitat and possession of LLINs. This geographical study made the municipality of Kouandé eligible for IRS and for this study [6].

The entomological study found that the mosquitoes of the Kouandé municipality are very sensitive to Bendiocarb $1 \%$ (95\%), which is the insecticide used for IRS [7]. It should be noted that the joint strategy (IRS + LLINs) was introduced to the Kouandé municipality in June 2011, prior to that date only the LLINs strategy was used.

The Municipality of Copargo was chosen because of its geographical position and its cultural similarity with the Kouandé municipality. It covers an area of $876 \mathrm{sq}$ $\mathrm{km}$ and is bordered by the municipalities of Natitingou and Kouandé (North), Djougou and Ouaké (South and East) and by the Republic of Togo (West). The climate, Sudano-Guinean, is characterized by a rainy season, from mid-April to mid-October and a dry season from midOctober to mid-April. It is crossed and irrigated by several rivers. Its population is composed mostly of Yom Lokpas, who represent $83 \%$ of the population, and Fulani (7.2\%) [8]. The dominant religions are traditional religion (70\%), Islam (18\%) and Christianity (8\%). Like Kouandé municipality the strategy of LLINs-only had been used previously.

Figure 1 shows the characteristics of the studied municipalities.

\section{Sampling and data collection}

This was a cross-sectional study, and was carried out from June 2011 to July 2011, just after the implementation of the IRS. The collection of data consisted mainly of a series of interviews with people responsible for control of resources (managers of malaria program and partners for the implementation of the IRS), and the use of documents provided by them.

Complementary data were obtained from household surveys. Two cohort studies had previously characterized the collection of epidemiological data: a retrospective 


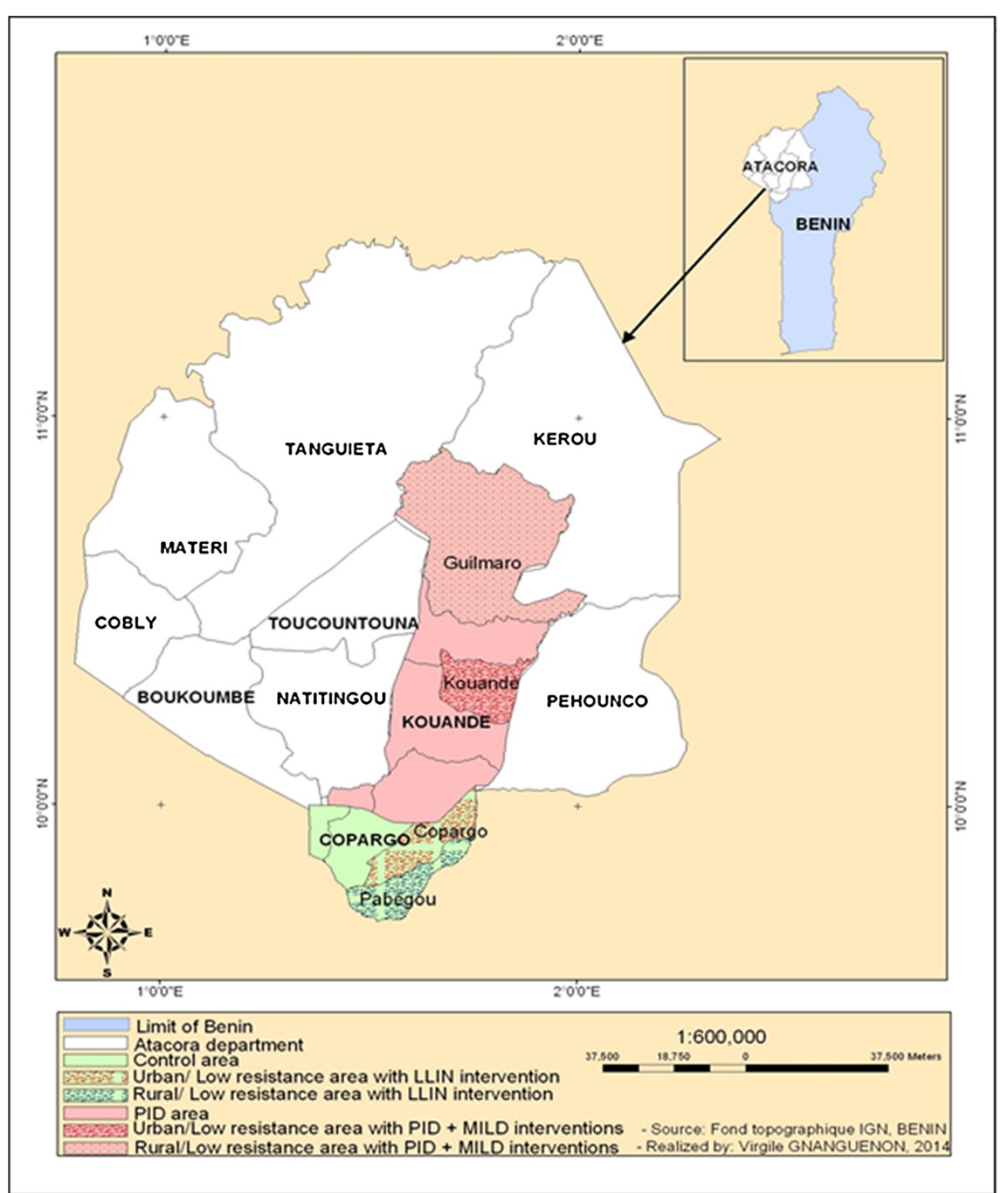

Figure 1 Characteristics of the municipalities studied.

study made one year before the IRS (May 2010-May 2011), and a study performed prospectively during and after the IRS (May 2011-May 2012).Although a quick diagnosis test was introduced by the malaria program, the lack of staff and the slowness of staff to change behavior or adopt new methods or protocols led to the finding that the method for screening malaria cases in the two periods remained the same. So the malaria case detection approach is based on probable cases (based on clinical signs: fever, chill, vomiting, body aches), and confirmed cases (quick diagnosis test). Indeed for the retrospective phase 9,381 malaria cases were reported, broken down as follows: - 1,977 cases at Kouandé- Centre, 1,377 cases at Guilmaro, 2,471 cases at Copargo- Centre and 3,556 cases at Pabégou. Similarly for the prospective phase, 6,155 malaria cases (probable and confirmed) were reported, broken down respectively as follows :- 590 cases at Kouandé- Centre, 969 cases at
Guilmaro, 2,120 cases at Copargo- Centre and 2,476 cases at Pabégou.

For the economic cost studies, two cross-sectional studies were conducted in May 2011 (before IRS) and May 2012 (after IRS). 400 households in May 2011 and 405 in May 2012 were selected by systematic random sampling from the register of patients seen at the health centers of the municipalities selected. Therefore, 100 households were selected per municipality.

A similar approach was used for a case control study but in that study we compared the economic cost of malaria prevented by case for each strategy and by type of municipality.

\section{Method of calculating cost-effectiveness ratios}

The approach used for calculating the cost-effectiveness ratio was inspired by the conceptual framework of Audibert 
[9] and the approach developed in Bhatia et al. [10] and HAS [11].

The conceptual framework proposed by Audibert has five phases. Each stage corresponds to a level of achievement of objectives (indicators) and corresponding economic evaluation methods:

Phase I is the calculation of the actual cost $(\mathrm{C})$ of the implementation of the IRS and the distribution of insecticide-treated nets in the municipalities of Kouandé- Centre and Guilmaro.

Phase II is the implementation of program activities. It is possible to calculate at this stage the cost per type of activity conducted. This ratio does not represent the cost-effectiveness of the program (the activities are not a result), but it can give a relative idea of the cost of the different activities. In this case, the ratio is given by the formula:

$$
\begin{aligned}
& C A 1=\text { Cost } 1 / \text { protected person } \\
& C A 2=\text { Cost } 2 / \text { LLIN distributed }
\end{aligned}
$$

Phase III concerns the changes in behavior observed in vectors and/or individuals as a result of the implementation of the IRS and the distribution of LLINs. This has been discussed at length in the entomological study and the KAP study.

Phase IV concerns the result from the epidemiological point of view, regarding the reduction of mortality/ morbidity due to malaria. This calculation is based on data collected in routine care facilities and health services using a data collection form designed for this purpose. The number of malaria cases prevented is given by the formula:

$$
E=E 2-E 1
$$

$\mathrm{E}=$ Effectiveness; $\mathrm{E} 1$ = Total malaria cases recorded one year before the IRS;

E2 = Total malaria cases recorded one year after the IRS. Phase $\mathrm{V}$ is the calculation of the cost-effectiveness ratio which is given by the formula:

$$
\mathbf{C E}=[\mathbf{C}-(\mathbf{S 1}+\mathbf{S 2})] / \mathbf{E}
$$

Where, $\mathrm{CE}$ is the cost effectiveness ratio, $\mathrm{C}$ is the cost of implementing each intervention, $\mathrm{S} 1$ the cost savings for healthcare facility, S2 the cost savings for household, and $\mathrm{E}$ is the incremental effectiveness (number of malaria cases prevented).

We did not find in the literature, an evidence-based study using both IRS and LLIN strategies together. However it has been shown that these two strategies used apart give the same effect and have the same cost effectiveness ratio [10,11].
We consider for our study that the IRS + LLINs strategy is cost effective if:

$$
\begin{gathered}
\text { Cost-Effectiveness Ratio LLINs + IRS } \\
<\text { Cost-Effectiveness Ratio LLINs }
\end{gathered}
$$

It follows from this equation that the more the RCE ratio of LLINs + IRS is less than the RCE of LLINs, the more it is cost effective.

- Estimated cost of implementation of the IRS Cost $1=$ Cost Unit/people protected $\times$ number of individuals protected

- Estimation of the cost of distribution of LLINs Cost $2=($ Cost of buying one LLINs $\times$ Number of LLINs distributed) + total cost of distribution

- Estimation of cost savings for the health care facility (S1):

For health care facilities, the resources used for the management of malaria consist of: the cost of the medical consumables used (CoM), the monetary equivalent of time spent by agents for the treatment of each patient (MOD), and the cost of IEC/CCC interventions for malaria (CIEC). For $\mathrm{E}$ cases prevented, total cost savings is given by the formula:

$$
S 1=[(C o M+M O D) \times E] .
$$

The cost of interventions IEC / CCC (CIEC) was not considered in estimating the gain for the health service because it is a fixed cost that does not vary with the number of cases, and should be continued because malaria has not been eliminated. The cost of medical consumables affects the other inputs except TDR and GE (included in the economic cost of the patient). CoM includes the costs of cotton and alcohol. The Wear small equipment consultation (thermometer, stethoscope, blood pressure, etc.) has not been valued, because the value of this equipment is too low to be annualized and shared between all the treated malaria cases. Because we do not have precise values for quantities used for each patient, the cost of consumables used has not been taken into account. Finally, the time spent by health staff to support minor and severe malaria cases was evaluated from informal interviews with the health staff in post (doctor, nurse or midwife responsible) in the hospital or health center and by direct observation (discrete timing during supervision by a $\mathrm{PhD}$ student). This time was valued at the hourly rate for the relevant category of health worker (obtained from payroll records) to estimate the cost to the hospital or health center. 
Finally, the total for the cost savings by the health care provider becomes:

$$
\mathbf{S 1}=\mathbf{M O D} * \mathbf{E}
$$

\section{Estimation of cost savings by patient/community (S2)}

Regarding the patient and his/her accompaniment, the cost savings saved by the community are given by the formula:

S2 $=$ average economic cost Patient pre-intervention $\times \mathbf{E}$

\section{Data analysis}

Microsoft Office Excel 2007 software was used for calculations. The sensitivity analysis of the cost-effectiveness ratio was performed to assess the variability of the incremental cost and effectiveness, taking into account the surrounding uncertainty with STATA 11 [12].

\section{Ethical approval}

The study reported in this paper was carried out with the approval of the National Ethic Committee for Research (CNERES) in Health of Ministry of Health - No. 007 of 25 May 2010.

\section{Results}

\section{Estimation of the differential effectiveness}

\section{Estimated cost of the intervention}

According to the performance report of the IRS (round1) in Atacora department, $82 \%$ of individuals in the Kouandé municipality were protected [13]. This rate assigned to the municipalities of Kouandé Centre and Guilmaro allows calculation of the respective costs of implementation of the IRS. According to the same source [13], the average cost per person protected is 4USD (2,000 FCFA).

For the distribution of LLINs, we used the budget by municipality for the malaria program. This allowed identification of the unit cost for the distribution of LLINs [14] (Table 1).
Estimation of resources saved by health care facility (S1) For the calculation of malaria cases averted we used the routine epidemiological data one year before and after IRS intervention (Table 2).

Tables 3 and 4 summaries the calculation of the MOD for key staff involved in the management of malaria by municipality, for IRS + LLINs (Table 3), and for LLINsonly (Table 4).

Table 5 below provides a synthesis of the calculation of the costs saved by health care providers because of the implementation of the IRS and LLINs. It is given by the formula:

$\mathrm{S} 1=$ cost savings from the uncomplicated malaria cases prevented + cost savings from the severe malaria cases prevented.

\section{Estimation of resources saved by households (S2)}

$$
\begin{aligned}
\mathrm{S} 2= & \text { Cost saving from the uncomplicated cases averted } \\
& + \text { Cost saving from the severe malaria cases averteda }
\end{aligned}
$$

Table 6 provides a summary of the calculation of the cost savings by households because of the implementation of the IRS and LLINs. It is given by the formula:

\section{Calculation of cost-effectiveness ratios by municipality}

The intention of this paper is to calculate the costeffectiveness ratio in each of the four municipalities selected for the study to facilitate the comparison between urban and rural. In the control areas (Copargo- Centre and Pabégou) there was a mass distribution of LLINs, and in the intervention area (Kouandé-Centre and Guilmaro) there was in addition to the mass distribution of LLINs, the implementation of IRS.

This interesting context has allowed us to calculate the cost effectiveness ratio by municipality which is given by the formula:

$$
C E=[C-(S 1 S 2)] / E
$$

Table 7 provides a summary of the results of the calculations for the cost-effectiveness ratio by municipality.

Table 1 Summary of calculations for the unit cost of LLIN distribution

\begin{tabular}{lllll}
\hline Municipalities & $\begin{array}{l}\text { Number of LLINs } \\
\text { distributed }\end{array}$ & $\begin{array}{l}\text { Unit purchase } \\
\text { cost of LLINs }\end{array}$ & $\begin{array}{l}\text { Total cost of } \\
\text { LLINs bought } \\
\text { (FCFA) }\end{array}$ & $\begin{array}{l}\text { Other fees } \\
\text { (transport/distribution } \\
\text { cost) (FCFA) }\end{array}$ \\
\hline COPARGO & 13,017 & 2,755 & $35,860,687$ & 436,666 \\
GUILMARO & 12,151 & 2,755 & $33,474,628$ & 724,562 \\
(FCFA) \\
KOUANDE & 14,183 & 2,755 & $39,074,088$ & 702,527 \\
PABEGOU & 6,951 & 2,755 & $19,149,546$ & 371,368
\end{tabular}


Table 2 Summary of the calculation of the differential effectiveness

\begin{tabular}{lllll}
\hline Municipalities & $\begin{array}{l}\text { Type of } \\
\text { malaria }\end{array}$ & $\begin{array}{l}\text { Number } \\
\text { of cases } \\
\text { one year } \\
\text { before (E1) }\end{array}$ & $\begin{array}{l}\text { Number } \\
\text { of cases } \\
\text { one year } \\
\text { after (E2) }\end{array}$ & $\begin{array}{l}\text { Differential } \\
\text { effectiveness } \\
\text { (E) } \\
\text { (E1 - E2) }\end{array}$ \\
\hline COPARGO & Uncomplicated & 2,056 & 1,805 & 251 \\
& Severe & 415 & 315 & 100 \\
GUILMARO & Uncomplicated & 1,283 & 891 & 392 \\
& Severe & 94 & 78 & 16 \\
KOUANDE & Uncomplicated & 1,721 & 486 & 1,235 \\
& Severe & 256 & 104 & 152 \\
PABEGOU & Uncomplicated & 3,399 & 2,342 & 1,057 \\
& Severe & 157 & 134 & 23 \\
\hline
\end{tabular}

Source: Routine epidemiological data collection.

\section{Sensitivity analysis}

The sensitivity analysis enables measurement of the variability of the results taking into account the uncertainty surrounding them, to provide an assessment of the robustness of the results.
Analyzes performed on the cost-effectiveness ratio show that it is sensitive to changes in the unit purchase cost of nets, insecticide, the workforce and changes to effectiveness [11].

This study was conducted over a relatively short period (1 year), the variability of unit purchase cost of nets, insecticide (bendiocarb), and the labor for resource people suitably qualified for the project, is almost zero.

The variability of the incremental effectiveness over the same period (1 year), was calculated from data obtained in routine health facilities of the districts selected for the study.

Several factors could influence the number of cases of malaria averted: the frequentation rate of services, geographical accessibility (especially Guilmaro), and the quality of services.

The parallel epidemiological cohort study has enabled reduction in the risk of error by calculation of the confidence interval of the relative risk by type of area (urban and rural). All things being equal, it is concluded that the variability of the cost-effectiveness ratio is proportional to the variability of relative risk.

Table 3 Summary of calculating the MOD for key staff involved in the management of malaria by the municipality with IRS + LLINs

\begin{tabular}{|c|c|c|c|c|c|c|c|c|}
\hline \multirow{3}{*}{$\begin{array}{l}\text { Management of } \\
\text { malaria step and } \\
\text { key personal used }\end{array}$} & \multicolumn{4}{|c|}{ Uncomplicated malaria } & \multicolumn{4}{|c|}{ Severe malaria } \\
\hline & \multicolumn{2}{|c|}{ Kouandé Centre } & \multicolumn{2}{|c|}{ Guilmaro } & \multicolumn{2}{|c|}{ Kouandé-Centre } & \multicolumn{2}{|c|}{ Guilmaro } \\
\hline & $\begin{array}{l}\text { Duration } \\
(\mathrm{mn})\end{array}$ & $\begin{array}{c}\text { Cost } \\
\text { (FCFA) }\end{array}$ & $\begin{array}{c}\text { Duration } \\
(\mathrm{mn})\end{array}$ & $\begin{array}{c}\text { Cost } \\
\text { (FCFA) }\end{array}$ & $\begin{array}{c}\text { Duration } \\
(\mathrm{mn})\end{array}$ & $\begin{array}{l}\text { Cost } \\
\text { (FCFA) }\end{array}$ & $\begin{array}{c}\text { Duration } \\
(\mathrm{mn})\end{array}$ & $\begin{array}{c}\text { Cost } \\
\text { (FCFA) }\end{array}$ \\
\hline \multicolumn{9}{|l|}{ Reception } \\
\hline AS & 15 & 111.6 & 10 & 74.4 & 15 & 111.6 & 10 & 74.4 \\
\hline \multicolumn{9}{|l|}{ IS (nurse assistant) } \\
\hline \multicolumn{9}{|l|}{ Consultation } \\
\hline Doctor/Gynaecologist & 15 & 461.4 & & & 15 & 461.4 & & \\
\hline Nurse/Midwife & & & 15 & 195.5 & & & 15 & 195.5 \\
\hline \multicolumn{9}{|l|}{ IS (Nurse assistant) } \\
\hline \multicolumn{9}{|l|}{ Diagnostic confirmation } \\
\hline AS of levy & 10 & 74.4 & & & 10 & 74.4 & & \\
\hline TSL & 45 & 736.9 & & & 45 & 736.9 & & \\
\hline \multicolumn{9}{|l|}{ Treatment } \\
\hline Nurse /Midwife & 5 & 65.2 & & & 5 & 65.2 & 49.5 & 645.1 \\
\hline AS (carer) & & & & & & & 49.5 & 368.2 \\
\hline \multicolumn{9}{|l|}{ Pharmacy } \\
\hline AS/Commis (carer) & 5 & 37.2 & 5 & 37.2 & 10 & 37.2 & 5 & 52.1 \\
\hline \multicolumn{9}{|l|}{ Hospitalization } \\
\hline Doctor & & & & & 30 & 922.8 & & \\
\hline Nurse/Midwife & & & & & 4,320 & $56,295.39$ & & \\
\hline AS & & & & & 4,320 & $32,137.04$ & & \\
\hline TOTAL & \multicolumn{2}{|c|}{$M O D=1,486.7$} & \multicolumn{2}{|c|}{$M O D=307.1$} & \multicolumn{2}{|c|}{$M O D=88,432.4$} & \multicolumn{2}{|c|}{$M O D=1,335.3$} \\
\hline
\end{tabular}

Source: Economic Survey study and synthesis of findings supervision of doctoral and human resources data. 
Table 4 Summary of calculating the MOD for key staff involved in the management of malaria by municipality with LLINs alone

\begin{tabular}{|c|c|c|c|c|c|c|c|c|}
\hline \multirow{3}{*}{$\begin{array}{l}\text { Management of } \\
\text { malaria step and } \\
\text { key personal used }\end{array}$} & \multicolumn{4}{|c|}{ Uncomplicated malaria } & \multicolumn{4}{|c|}{ Severe malaria } \\
\hline & \multicolumn{2}{|c|}{ Copargo-Centre } & \multicolumn{2}{|c|}{ Pabégou } & \multicolumn{2}{|c|}{ Copargo-Centre } & \multicolumn{2}{|c|}{ Pabégou } \\
\hline & $\begin{array}{c}\text { Duration } \\
(\mathrm{mn})\end{array}$ & $\begin{array}{l}\text { Cost } \\
\text { (FCFA) }\end{array}$ & $\begin{array}{l}\text { Duration } \\
(\mathrm{mn})\end{array}$ & $\begin{array}{c}\text { Cost } \\
\text { (FCFA) }\end{array}$ & $\begin{array}{l}\text { Duration } \\
(\mathrm{mn})\end{array}$ & $\begin{array}{c}\text { Cost } \\
\text { (FCFA) }\end{array}$ & $\begin{array}{l}\text { Duration } \\
(\mathrm{mn})\end{array}$ & $\begin{array}{c}\text { Cost } \\
\text { (FCFA) }\end{array}$ \\
\hline \multicolumn{9}{|l|}{ Reception } \\
\hline AS (carer) & 15 & 111.6 & 10 & 74.4 & 15 & 111.6 & 10 & 74.4 \\
\hline \multicolumn{9}{|l|}{ IS } \\
\hline \multicolumn{9}{|l|}{ Consultation } \\
\hline Doctor/Gynecologist & 15 & 461.4 & & & 15 & 461.4 & & \\
\hline Nurse/SFE & & & 15 & 146.5 & & & 15 & 195.5 \\
\hline \multicolumn{9}{|l|}{ IS (nurse assistant) } \\
\hline \multicolumn{9}{|l|}{ Diagnostic confirmation } \\
\hline AS of levy & 10 & 74.4 & & & 10 & 74.4 & & \\
\hline TSL & 45 & 736.9 & & & 45 & 736.9 & & \\
\hline \multicolumn{9}{|l|}{ Treatment } \\
\hline Nurse /Midwife & 5 & 65.2 & & & 8 & 104.3 & 81.5 & 795.8 \\
\hline AS (carer) & & & & & 8 & 59.5 & 81.5 & 606.3 \\
\hline \multicolumn{9}{|l|}{ Pharmacy } \\
\hline AS/Commis & 5 & 37.2 & 5 & 37.2 & 10 & 37.2 & 5 & 52.1 \\
\hline \multicolumn{9}{|l|}{ Hospitalization } \\
\hline Doctor & & & & & 30 & 922.8 & & \\
\hline Nurse/Midwife & & & & & 4,320 & $28,147.7$ & & \\
\hline AS & & & & & 4,320 & $16,068.5$ & & \\
\hline TOTAL & \multicolumn{2}{|c|}{$M O D=1,486.7$} & \multicolumn{2}{|c|}{$M O D=258.1$} & \multicolumn{2}{|c|}{$M O D=46,724.2$} & \multicolumn{2}{|c|}{$M O D=1,724.1$} \\
\hline
\end{tabular}

Source: Economic Survey study and synthesis of findings supervision of doctoral and human resources data.

This estimation approach for the confidence interval of the cost effectiveness ratio has already been used by other authors, for instance Manns et al. [15] and Betancourt et al. [16].

Table 8 provides a summary of the variability of the cost-effectiveness in proportion to the variability of the relative risk (RR) ratio.

\section{Discussion}

The discussion will focus on the limitations of the study and the analysis of the cost-effectiveness ratios obtained by municipality.

\section{Limitations of the study}

This study has the following limitations:

- from an epidemiological point of view, it would have been interesting to have confirmation of the rate of diagnosis of malaria (TDR/GE) in the monthly reporting of malaria cases recorded in health facilities. It is not very low and is close to $80 \%$ per site. A bigger screening study (TDR) at community level would have strengthened the epidemiological results;

- from an economic point of view, the fact that the cost calculation is based on the history of the

Table 5 Estimation of the cost savings by health care providers (S1) by municipality

\begin{tabular}{|c|c|c|c|c|c|}
\hline Municipalities & $\begin{array}{c}\text { Number of } \\
\text { uncomplicated } \\
\text { malaria cases averted } \\
\text { (a) }\end{array}$ & $\begin{array}{l}\text { Cost of the MOD } \\
\text { for uncomplicated } \\
\text { malaria case } \\
\text { (b) }\end{array}$ & $\begin{array}{l}\text { Number of severe } \\
\text { malaria cases } \\
\text { averted } \\
\text { (c) }\end{array}$ & $\begin{array}{l}\text { MOD cost for } \\
\text { severe malaria } \\
\text { case (FCFA) } \\
\text { (d) }\end{array}$ & $\begin{array}{l}\text { Cost savings } \\
\text { for health } \\
\text { providers (FCFA) } \\
\left(a^{*} b\right)+\left(c^{*} d\right)\end{array}$ \\
\hline Copargo Centre & 251.0 & $1,486.7$ & 100 & $46,724.2$ & $5,045,581.7$ \\
\hline Guilmaro & 392.0 & 307.1 & 16.0 & $1,335.3$ & $141,748.0$ \\
\hline Kouandé Centre & $1,235.0$ & $1,486.7$ & 152.0 & $88,432.4$ & $15,277,799.0$ \\
\hline Pabégou & $1,057.0$ & 258.0 & 23.0 & $1,724.1$ & $312,466.0$ \\
\hline
\end{tabular}

Source: Epidemiological and cost data collection. 
Table 6 Summary of calculation of cost savings (FCFA) by household (S2) by municipality

\begin{tabular}{|c|c|c|c|c|c|}
\hline Municipalities & $\begin{array}{c}\text { Number of } \\
\text { uncomplicated } \\
\text { malaria cases averted } \\
\text { (a) }\end{array}$ & $\begin{array}{l}\text { Average economic } \\
\text { cost per uncomplicated } \\
\text { malaria case } \\
\text { (b) }\end{array}$ & $\begin{array}{l}\text { Number of severe } \\
\text { malaria cases } \\
\text { prevented } \\
\text { (c) }\end{array}$ & $\begin{array}{l}\text { Average economic } \\
\text { cost per severe } \\
\text { malaria case } \\
\text { (d) }\end{array}$ & $\begin{array}{r}\begin{array}{r}\text { Cost savings } \\
\text { by household }\end{array} \\
\left(a^{*} b\right)+\left(c^{*} d\right)\end{array}$ \\
\hline Copargo Centre & 251.0 & 1486.7 & 100 & $46,724.2$ & $5,045,581.7$ \\
\hline Guilmaro & 392.0 & 307.1 & 16.0 & $1,335.3$ & $141,748.0$ \\
\hline Kouandé Centre & $1,235.0$ & $1,486.7$ & 152.0 & $88,432.4$ & $15,277,799.0$ \\
\hline Pabégou & $1,057.0$ & 258.0 & 23.0 & $1,724.1$ & $312,466.0$ \\
\hline
\end{tabular}

patient, and documents which mainly concern the patient's experience of the disease could lead to a bias in the quality of the information received;

- the expenditure saved by providers has been underestimated, because it was not possible to specify the exact quantities of inputs used and the estimate of cost for the very basic medical equipment.

These limitations were minimized to ensure the best quality of data collected.

\section{Analysis of cost-effectiveness ratios by municipality}

The main challenge for policy makers is how to use the scarce resources allocated to the fight against malaria in the most efficient possible way to maximize the socioeconomic benefits for households and health facilities. This study estimated the cost-effectiveness ratios of the implementation of the strategy LLINs + IRS in the intervention zone compared to the control zone which used the LLINs-only strategy. The results show that the cost per averted case of malaria is 38,933 FCFA at KouandéCentre against 85,572 FCFA at Copargo-Centre, and 174,729 FCFA at Guilmaro, and 15,941 FCFA at Pabégou. The result for Guilmaro could be explained by low attendance due to the long distances to access health centers, about $20 \mathrm{~km}$ on average (information collected from the head nurse post at Guilmaro), and due to the big deterioration of roads in the rainy season. These results show that the LLINs + IRS strategy is cost effective in urban zones; in rural zones it is the opposite. However, if we consider the results of the entomological and epidemiological studies performed at the same time, the Related Risks (RR) were respectively 0.25 and 0.22 , significantly lower than 1 with upper limits (95\%) respectively of 0.279 and 0.240 , which are also less than 1 . This clearly means that there is an almost 4 times lower risk of contracting malaria at Kouandé- Centre than at CopargoCentre, and there is an almost 4.5 times lower risk of contracting malaria at Guilmaro than Pabégou.

IRS is a protective factor against the occurrence of malaria in the municipalities of Kouandé Centre and Guilmaro. We conclude that from the public health point of view the LLINs + IRS strategy is effective and necessary in the high malaria endemic zone.

The opposite results were seen by Corbel et al. with the randomized cluster and controlled trial in 28 villages in southern Benin [17]. They assessed four malaria vector control interventions: LLIN targeted coverage of pregnant women and children under 6 (TLLIN, reference group), LLIN full coverage of all sleeping units (ULLIN), TLLIN plus full coverage of carbamate-IRS applied every 8 months (TLLIN + IRS), and ULLIN plus full coverage of CTPS (carbamate-treated plastic sheetings) lining upto the upper part of the house walls (ULLIN + CTPS). The results showed that there is no significant reduction of malaria morbidity, infection, and transmission when combining LLIN with IRS or LLIN with CTPS compared to a control background of LLIN coverage. This study, unlike ours, was conducted in a medium-endemic malaria area. This difference may explain the discrepancy between the results relative to the malaria morbidity reduction observed.

Moreover, if we consider the results of the sensitivity analysis for the cost effectiveness ratio, only the incremental effectiveness is influenced by the frequentation rate of services, geographical accessibility (especially Guilmaro), and the quality of services. This shows that the costeffectiveness ratio obtained at Guilmaro may be a denominator problem and due in particular to geographic accessibility. Indeed, the fact that Guilmaro is difficult to access and inaccessible in the rainy season (the period of high malaria transmission) greatly influences the health center frequentation by communities. The frequentation rates calculated in the Guilmaro health center in 2010, 2011 and 2012 were respectively 15\%, 10\% and 13\%, as compared to $37.8 \%, 39.45 \%$ and $38.59 \%$ at Pabégou. Over the same period, the average frequentation rates of health services at the national level were respectively $46.8 \%$, $45.4 \%$ and $51.4 \%$ [18-20]. So a large proportion of malaria cases would be at the community level, especially at Guilmaro. This situation raises again the problem of the choice of the elements of cost used to measure the effectiveness of the strategies, and the data collection.

Several authors, Audibert [9] and Evans et al. [21], have shown the importance of the choice of the cost structure 


\section{Table 7 Calculation of Cost-Effectiveness (CE) ratios by municipality}

\begin{tabular}{|c|c|c|c|c|c|c|c|c|c|c|}
\hline $\begin{array}{l}\text { Type } \\
\text { of zone }\end{array}$ & Boroughs & $\begin{array}{l}\text { Population } \\
\text { protected (a) }\end{array}$ & $\begin{array}{l}\text { Cost per person } \\
\text { protected (b) }\end{array}$ & $\begin{array}{l}\text { Number of LLINs } \\
\text { distributed (c) }\end{array}$ & $\begin{array}{l}\text { Cost per LLINs } \\
\text { distributed (d) }\end{array}$ & $\begin{array}{l}\text { Cost savings } \\
\text { for health } \\
\text { providers (S1) }\end{array}$ & $\begin{array}{l}\text { Cost savings } \\
\text { for the } \\
\text { communities (S2) }\end{array}$ & $\begin{array}{c}C \text { Intv }\left[\left(\left(a^{*} b\right)+\left(c^{*} d\right)\right)-\right. \\
(S 1+S 2)]\end{array}$ & $\begin{array}{c}\text { Number of } \\
\text { malaria cases } \\
\text { prevented (E) }\end{array}$ & $\begin{array}{l}\text { Cost effectiveness } \\
\text { ratio (CE) }\end{array}$ \\
\hline \multirow[t]{2}{*}{ Urban } & Copargo-centre & - & 2000 & 13017 & 2788,5 & 5045582 & 1216396,5 & 30035926 & 351 & 85572,4 \\
\hline & Kouandé-centre & 27316,0 & 2000 & 14183 & 2804,5 & 15277799 & 25130876,3 & 53999548 & 1387 & 38932,6 \\
\hline \multirow[t]{2}{*}{ Rural } & Pabégou & - & 2000 & 6951 & 2808,4 & 312466 & 1992917,7 & 17215805 & 1080 & 15940,6 \\
\hline & Guilmaro & 19188,0 & 2000 & 12151 & 2814,6 & 141748 & 1145220,8 & 71289236 & 408 & 174728,5 \\
\hline
\end{tabular}

According to the results this table shows that:

CE ratio of Kouandé Centre $<$ CE ratio of Copargo Centre; LLINs + IRS strategy is the most cost-effective in urban areas.

CE ratio of Guilmaro > CE ratio of Pabégou; LLINs + IRS strategy is the least cost-effective in rural areas. 
Table 8 Summary of sensitivity analysis of the cost-effectiveness ratio

\begin{tabular}{|c|c|c|c|c|}
\hline & \multicolumn{2}{|c|}{ Urban zone } & \multicolumn{2}{|c|}{ Rural zone } \\
\hline & Copargo Centre (LLINs) & Kouandé Centre (LLINs + IRS) & Pabégou (LLINs) & Guilmaro (LLINs + IRS) \\
\hline CE Ratio in function of RR CI 95\% & \multicolumn{2}{|c|}{$\mathrm{RR}=0.25[0.223 ; 0.279]$} & \multicolumn{2}{|c|}{$\mathrm{RR}=0.22[0.208 ; 0.240]$} \\
\hline Cost -effectiveness Ratio if $R R=$ lower limit & $79,753.5$ & $36,285.2$ & $15,071.1$ & $165,197.9$ \\
\hline Cost -effectiveness Ratio if $R R=$ average value & $85,572.4$ & $38,932.4$ & $15,940.6$ & $174,728.5$ \\
\hline Cost -effectiveness Ratio if $R R=$ upper limit & $95,498.8$ & $43,448.8$ & $17,389.7$ & $190,612.9$ \\
\hline
\end{tabular}

The average values of the Cost-Effectiveness Ratio (CER) are included in the range of variability, indicating that CER is stable, not sensitive to parameter change.

and the incremental effectiveness for the quality of the cost-effectiveness ratio. They add that before the costeffectiveness ratio can be robust, it must sample a substantial number of households, and use the same sample for the epidemiological study and the economic study.

Similar results were obtained by Bhatia et al. in their study [10]. This study, unlike ours, was conducted in low malaria endemic areas. They compared 2 interventions to control malaria in terms of the epidemiological, parasitological, entomological, sociological and economic level of the community, using a randomized trial of three arms covering 3 of the malaria areas of Surat district. It appears from this study that the average cost per case averted was $70 \%$ higher for IRS than for LLINs. This difference was statistically significant for the cost and the confidence intervals overlap. They conclude that both IRS and LLINs are effective in preventing malaria. They add that this conclusion is robust to the likely changes in key parameters such as personnel and the cost of inputs.

Also, Morel et al. [12] worked on two highly malaria (Plasmodiumfalciparum) endemic areas in Eastern, South and West Africa. The interventions compared were: LLINs, IRS, support for malaria cases with chloroquine, support for cases with sulfadoxine-pyrimethamine (SP), management of cases with non-artemisinine derivatives (CQ-SP), management of cases with artemisinine derivatives (Coaterm), and intermittent presumptive treatment for pregnant women. Disability Adjusted Life Year (DALY) was used as the unit of measurement of effectiveness. The results show that in West Africa, the management of cases with an artemisinine-based combination at $80 \%$ target coverage for the intervention is the most cost effective, while in East Africa and South Africa a target coverage of $95 \%$ is required. Similarly, in the two regions, the ultimate result (95\%) involved the use of both derivatives of artemisinine, LLINs or IRS, and intermittent presumptive treatment. The same study also shows that the IRS and LLINs have a similar cost-effectiveness ratio.

In light of the above, and in view of the entomological and epidemiological data which show a significant decrease of the inoculation rate [22], and the incidence of the malaria, it can be said that the LLINs + IRS strategy is cost effective in highly malaria endemic area (both urban and rural), if communities use LLINs even when it is hot.

\section{Conclusion}

In this paper we have estimated, via the development of epidemiological, entomological and economic indicators, the results of the implementation of IRS, the economic gains made to health facilities and households, and the cost-effectiveness ratio by malaria case averted in the four selected boroughs. It appears from this study that the LLINs + IRS strategy is more cost effective in urban areas than the LLINs-only strategy, while the opposite result is observed in rural areas. However, this result in the rural area of Guilmaro would have been more favorable if we had had a better estimate of the number of cases of malaria by integrating data at the community level. A more detailed study over a longer period, including diagnosis at the community level, and extended to other municipalities should be commissioned to minimize bias related to low frequentation of health facilities before deciding to extend IRS to Donga, Borgou and Alibori departments.

\section{Competing interests}

The authors declare that they have no competing interests.

\section{Authors' contributions}

CPM: designed and implemented the study, supervised the collection and analysis of data and contributed to the drafting and editing of the manuscript. MA: assisted in design of the study, analysis of data, drafting and editing of the manuscript. AM: assisted in design of the study, analysis of data, drafting and editing of the manuscript. All authors read and approved the final manuscript.

\section{Authors' information}

CPM: Economist specialized in Public Health and Health Economics, PhD student.

MA: Professor of Health Economics and Director of Research at CNRS, co-promoter of the thesis.

AM: Professor of parasitology and bacteriology of the University of CAMES, promoter of the thesis.

\section{Acknowledgements}

We would like to thank the regional health director of Atacora/Donga, the manager of the malaria program, CREC and RTI, the lead doctors and head nurses of the municipalities of Copargo and Kouandé, our investigators, and especially the households who accepted to participate in this study. We also thank the two anonymous reviewers for their helpful and constructive comments. 
Financial competing interests

This article is a part of a PhD in Health Economics and fully financed by equity. So the authors declare that they have no financial competing interests.

\section{Author details}

${ }^{1}$ Interdisciplinary Graduate School: Space, Culture and Development, Faculty of Humanities Arts and Social Sciences, University of Abomey-Calavi, 01 BP526 Cotonou, Benin. ${ }^{2}$ Centre for Study and Research on International Development, National Center of Scientific Research, 65 Boulevard François Mitterrand, 63000 Clermont-Ferrand, France. ${ }^{3}$ Faculty of Health Sciences of Cotonou, University of Abomey-Calavi, 01BP188 Cotonou, Benin.

Received: 27 February 2014 Accepted: 15 September 2014

Published: 26 September 2014

\section{References}

1. World Health Organization: World Malaria Report 2013. Geneva: 2013.

2. de la Santé M: Annuaire des Statistiques Sanitaires 2012. Cotonou: 2013

3. Institut National de la Statistique et de l'Analyse Economique: Enquête Démographique et de Santé et à Indicateurs Multiples du Bénin EDS-MICS-IV 2011-2012. Cotonou: 2012.

4. Banque Mondiale: Programme Renforcé De La Banque Mondiale Pour La Lutte Contre Le Paludisme En Afrique. 2009.

5. Programme d'appui au démarrage des communes/Cabinet Afrique Conseil 2006: Monographie de la commune de Kouandé au Bénin. 50.

6. Nséka Vita T: Etude de la reconnaissance géographique du département de l'Atacora. Cotonou: Rapport d'étude; 2010.

7. Akogbéto M: Entomological database in preparation for the implementation of Indoor Residual Spraying (IRS) in the department of Atacora. Cotonou: Final Report; 2011.

8. Programme d'appui au démarrage des communes/Cabinet Afrique Conseil 2006: Monographie de la commune de Copargo au Bénin. 70.

9. Audibert M: Evaluation de la lutte anti-vectorielle : approche économique, Revue de Médecine Tropicale. 2009, 69:185-193.

10. Bhatia M, Julia F-R, Anne M: Cost-effectiveness of malaria control interventions when malaria mortality is low: insecticide-treated nets versus in-house residual spraying in India. Social Science \& Medicine 2004, 59:525-539.

11. Haute Autorité de Santé: Choix méthodologiques pour l'évaluation économique à la HAS. 83p Saint Denis: HAS; 2011.

12. Morel CM, Lauer JA, Evans DB: Cost effectiveness analysis of strategies to combat malaria in developing countries. BJM. doi:10.1136,2005.

13. Research Triangle Institute: Benin Spraying Performance Report. Indoor Residual Spraying Task Order One. Cotonou: USAID; 2011.

14. Ministère de la Santé/Programme National de Lutte contre le Paludisme: Rapport campagne de distribution 2011. Cotonou: 2011.

15. Manns BJ, Lee H, Doig CJ, Johnson D, Donaldson C: An economic evaluation of activated protein $C$ treatment for severe sepsis. $N$ Engl J Med 2002, 347:993-1000.

16. Betancourt M, McKinnon PS, Massanari RM, Kanji S, Bach D, Devlin JW: An evaluation of the cost effectiveness of drotrecogin alfa (activated) relative to the number of organ system failures. Pharmacoeconomics 2003, 21:1331-1340

17. Corbel V, Akogbeto M, Damien GB, Djenontin A, Chandre F, Rogier C, Moiroux N, Chabi J, Banganna B, Padonou GG, Henry MC: Combination of malaria vector control interventions in pyrethroid resistance area in Benin: a cluster randomised controlled trial. Published online june 7, 2012 doi:10.1016/S1473-3099(12)70081-6.

18. Direction de la Programmation et de la Prospective: Annuaire Des Statistiques Sanitaires 2011. In Annuaire Des Statistiques Sanitaires 2011. Edited by Ministère de la Santé, 130. Cotonou: Ministère de la Santé; 2012.

19. Direction de la Programation et de la Prospective: Annuaire Des Statistiques Sanitaires 2012. Edited by Ministère de la Santé, 150. Cotonou: Ministère de la Santé; 2013.

20. Direction de la Programmation et de la Prospective: Annuaire Des Statistiques Sanitaires 2010. Edited by Ministère de la Santé, 130. Cotonou: Ministère de la Santé; 2011.
21. Evans DB, Tessa Tan-Torres E, Taghreed A, Lim SS: Methods to assess the costs and health effects of interventions for improving health in developing countries. BJM. 10.1136, 2005.

22. Akogbéto M: Entomological database in prelude to the implementation of the second round of Indoor Residual Spraying (IRS) in Atacora department in Benin. Cotonou: 2012.

doi:10.1186/1478-7547-12-21

Cite this article as: Makoutodé et al:: Analysis of the cost-effectiveness of the implementation of Indoor Residual Spraying and distribution of Long-Lasting Insecticidal Nets in the municipality of Kouandé and municipality of Copargo in Benin. Cost Effectiveness and Resource Allocation 2014 12:21.

\section{Submit your next manuscript to BioMed Central and take full advantage of:}

- Convenient online submission

- Thorough peer review

- No space constraints or color figure charges

- Immediate publication on acceptance

- Inclusion in PubMed, CAS, Scopus and Google Scholar

- Research which is freely available for redistribution

Submit your manuscript at www.biomedcentral.com/submit 